\title{
Effect of changing dietary sodium on the airway response to histamine
}

\author{
P G J BURNEY, J E NEILD, C H C TWORT, S CHINN, T D JONES, W D MITCHELL, \\ C BATEMAN, I R CAMERON
}

From the Departments of Community Medicine, Medicine, and Chemical Pathology and Metabolic Disorders, United Medical and Dental Schools of Guy's and St Thomas's Hospitals, London

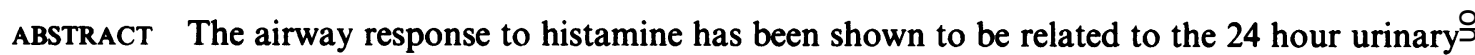
excretion of sodium. To assess whether this relation is likely to represent a direct causal association $\vec{a}_{\bar{c}}$ randomised double blind crossover trial of slow sodium ( $80 \mathrm{mmol} / \mathrm{day}$ ) was compared with placebos in 36 subjects having a low sodium diet. The dose of histamine causing a $20 \%$ fall in $F E V_{1}\left(P_{20}\right)$ waso 1.51 doubling doses lower when the men were taking sodium than when they were taking placebo $(\mathrm{p}<0.05)$. On the basis of $\mathrm{PD}_{10}$ values, the difference in men was 1.66 doubling doses of histamine $\vec{c}_{\infty}$ $(\mathrm{p}<0.05)$. There was no corresponding effect in women. Regressing $\mathrm{PD}_{10}$ against urinary excretion. ${ }^{\circ}$ of electrolytes with data from the two occasions during the trial and the measurements made before the trial showed a significant association with sodium excretion after allowance had been made for any effect associated with potassium or creatinine excretion, the latter being a marker of theo completeness of the urine collection. Again there was no corresponding effect among women. These $e_{\infty}^{\circ}$ findings are compatible with the differences in regional mortality data for England and Wales, which show a relation between asthma mortality and regional per person purchases of table salt for men buto을 not for women.

\section{Introduction}

The airway response to inhaled histamine is correlated with the 24 hour urinary excretion of sodium, a high rate of sodium excretion being associated with increased reactivity of the airway. ${ }^{.}$This might explain the strong association between regional mortality from asthma and purchases of table salt per person in England and Wales, an association that has been shown for adult men and children of both sexes, but not for adult women. ${ }^{2}$ It might also explain the relative lack of asthma in some of the world's poorest areas..$^{3-6}$

As the evidence for this association comes entirely from observational studies, however, it could be due to confounding.' We report here the results of an experimental study designed to test whether a change in the sodium content of the diet leads to a change in the airway response to histamine.

Address for reprint requests: Dr P G J Burney, Department of Community Medicine, United Medical and Dental Schools of Guy's and St Thomas's Hospitals (St Thomas's Campus), London SE1 7EH.

Accepted 13 October 1988
Methods

SUBJECTS

Volunteers of both sexes were recruited from outso patient clinics and hospital and medical school stafi and from two local general practices. Subjects all ha@ moderately severe asthma. Thirty five were taking inhaled beta agonists, 12 inhaled corticosteroids, eigh? cromoglycate, five theophylline, and three antihistamines. None was taking oral corticosteroids a․ the time of the trial.

\section{ASSESSMENT}

Subjects were assessed on four occasions. At each assessment measurements included bronchial res ponse to histamine, blood pressure, and skin seno sitivity to common inhaled allergens. Twenty fouñ hour collections of urine were made immediately before the second, third, and fourth visits and used too obtain estimates of 24 hour urinary sodium, potas? sium, and creatinine excretion.

HISTAMINE CHALLENGE

$\mathrm{FEV}_{1}$ and forced vital capacity (FVC) were measure 
with a dry spirometer (Vitalograph, Buckingham), the greater of two technically acceptable measurements within $5 \%$ of each other being used. The airway reponse to histamine was measured by a method similar to that described by Yan et al, ${ }^{7}$ with a hand held nebuliser. The FEV , was measured after an inhalation of normal saline, followed by doubling doses of histamine starting at a dose of $0.015 \mu \mathrm{mol}$ and continuing until either the $F E V_{1}$ fell to $80 \%$ of the post-saline value or a maximum dose of $0.72 \mu \mathrm{mol}$ had been administered. The doses that provoked a $10 \%$ and $20 \%$ fall in $\mathrm{FEV}_{1}$ from the post-saline value $\left(\mathrm{PD}_{10}\right.$, $\mathrm{PD}_{20}$ ) were calculated by fitting a curve to the doseresponse data as described by Chinn et al, ${ }^{8}$ with extrapolation to a dose of $1.45 \mu \mathrm{mol}$. Subjects were asked not to use beta agonist inhalers in the six hours before the tests.

\section{SKIN SENSITIVITY}

Skinprick tests were performed for type I (immediate) hypersensitivity to Dermatophagoides pteronyssinus, house dust, cat fur, Aspergillus niger, and mixed grass pollen, with diluent control. The maximum weal diameter and that at $90^{\circ}$ to it were measured at 10 minutes and the mean for all five allergens was calculated as the mean skin weal diameter. Subjects were asked not to use antihistamines within 24 hours of any test.

\section{HOUR URINE SPECIMENS}

Subjects were given verbal and written instructions on how urine should be collected. After voiding urine first thing in the morning they were asked to note the time and collect all their urine up to and including the first specimen of the following day, after which they were asked to record the time. The urine bottles contained methiolate preservative. Urine volume was measured and the concentration of sodium and potassium was estimated by means of ion specific electrodes. The creatinine concentration was measured by means of a modified Jaffe rate reaction.

\section{BLOOD PRESSURE}

Blood pressure was measured in the left arm by sphygmomanometry after the patient had been seated for at least 10 minutes. The second of two measurements made at least two minutes apart was recorded. Measurements were taken to the nearest $2 \mathrm{~mm} \mathrm{Hg}$.

\section{PROTOCOL}

The study had a double blind randomised crossover design. One week after the initial assessment subjects had a second assessment; they were put on a low sodium diet and asked to take either slow sodium ( $80 \mathrm{mmol} /$ day in two doses) or placebo tablets. After two weeks of this regimen a third assessment was carried out and the subjects changed to the alternative regimen. The fourth assessment was made after a further two weeks.

The study was approved by the local ethics committee. All subjects signed a consent form after the purpose of the research procedures and likely side effects had been explained.

\section{STATISTICAL METHODS}

For all estimates within subject analysis was used. Histamine $P_{10}$ and $P_{20}$ were transformed to the $\log _{10}$ scale and values for the slow sodium and placebo periods were compared. The significance of the difference was estimated by a paired $t$ test. When one treatment is given more commonly before another this may lead to bias if the order of the treatment itself influences the response. In one analysis where this was a possibility the effect was also calculated after account had been taken of the order in which treatments had been given. This and subsequent analyses of variance were performed with the program GLIM.' Where data on the airway response to histamine were censored (when $\mathrm{PD}_{10}$ and $\mathrm{PD}_{20}$ were greater than the highest dose for which an estimate was possible) the values were put at the censoring limit $(1.45 \mu \mathrm{mol})$. When both $\mathbf{P D}_{20}$ or $\mathbf{P D}_{10}$ values were censored the subject had to be excluded as change in reactivity could not be estimated. This accounts for the variable number of subjects in the different analyses.

Histamine $\mathrm{PD}_{10}$ was regressed against the 24 hour urinary excretion of sodium, potassium, and creatinine on the three occasions on which this information was collected. This was done in two ways: first by setting all censored values at the censoring limit as before, and secondly by using maximum likelihood to estimate the regression coefficients, a normal distribution of $\log P D_{10}$ values within subjects being assumed. ${ }^{10}$ This second analysis allowed use of the additional information that censored values were at or above rather than at the censoring limit. Similar analyses were performed to assess the relation of electrolyte excretion to airway reactivity after account had been taken of initial lung function, time since last bronchodilator, and whether the subjects were having a low salt diet.

Systolic and diastolic blood pressure were regressed against urinary electrolyte excretion.

\section{Results}

Of the 41 subjects recruited to the study, four had values for $\mathbf{P D}_{10}$ that were greater than the censoring limit on all four occasions or on all but the first occasion, and one failed to collect a urine specimen on the second and third occasions. These five subjects 
Table 1 Characteristics at the end of the introductory week of the 36 subjects included in the analysis

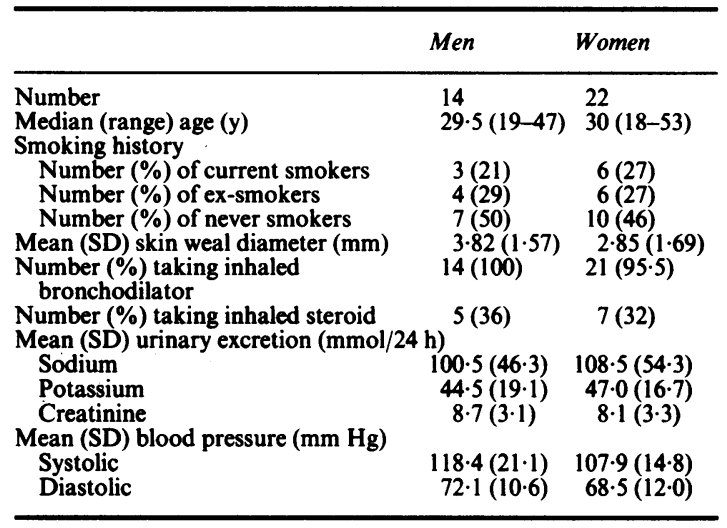

were excluded from further analysis, leaving 36 subjects in the study (14 men and 22 women). Details of these subjects are shown in table 1. Two further women failed to collect a urine specimen, one after taking placebo and the other after low sodium. Their results were not available for the comparison of these two regimens, though the information that was available was used to assess the within person association of airway reactivity and electrolyte excretion.

The mean sodium excretion at visit 2 before the introduction of the diet or tablets was $106 \mathrm{mmol} / 24$ hours (fig 1). After adoption of a low salt diet there was a mean (SEM) reduction in sodium excretion of 32 (17) $\mathrm{mmol} / 24$ hours in men and of 35 (9) mmol/24 hours in women. On taking the sodium tablets the men showed a mean increase in urinary sodium of $47(15) \mathrm{mmol} / 24$ hours and the women a mean increase of $43(12) \mathrm{mmol} /$ 24 hours compared with the period of the low sodium diet and placebo tablets.

There was an increase in $\mathrm{PD}_{10}$ in the men having the low sodium diet and a fall in $\mathrm{PD}_{10}$ after they had started the slow sodium tablets $(p<0.05)$. These changes were not seen among the women.

The $\mathrm{PD}_{20}$ when the men were taking sodium tablets was $1.51(95 \% \mathrm{CI}=0.31$ to 2.72$)$ doubling doses lower than when they were on placebo. The comparable figure for $\mathrm{PD}_{10}$ was 1.66 (95\% confidence interval (CI) $=0.38$ to 2.95 ) doubling doses in men (fig 2, table 2). Women had slightly higher $P_{20}$ and $P D_{10}$ values when taking sodium than when they were having placebo tablets, though the difference was not significant (fig 2, table 2). The effect of sodium on $\mathbf{P D}_{10}$ and $P_{20}$ was significantly different in men and women $(p<0.05)$. Adjustment for the order in which the treatments were given made no difference to the conclusions of the analysis.

Table 3 shows the association within subjects between $\mathrm{PD}_{10}$ and the urinary excretion of sodium,
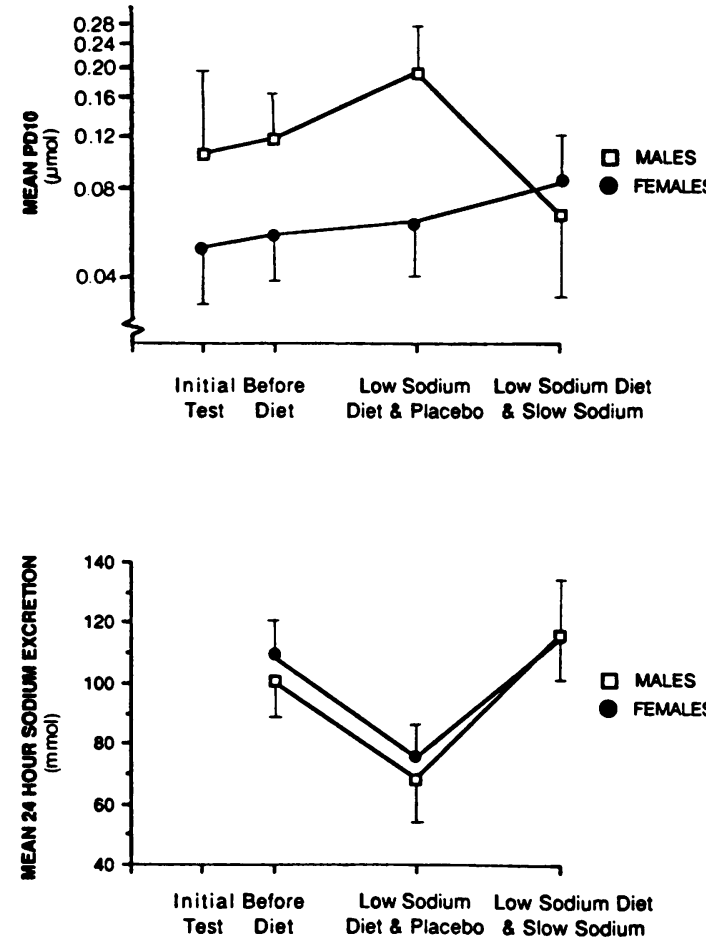

Fig 1 Geometric mean $P D_{10}$ values (airway reactivity) and 24 hour sodium excretion at different stages of the trial (the last two regimens were given in random order and not in the order shown by the diagram). Because of missing values taken account of in the estimation of mean differences in sodium excretion given in the text, those shown in the diagram are not exactly equivalent. The error bars represent between subject standard errors.

potassium, and creatinine. There was a significant negative relation between $\mathrm{PD}_{10}$ and urinary excretion of sodium for men but not for women. The relation with potassium is positive but not significant for both men and women. Adjustment for urinary excretion of $\frac{D}{O}$ creatinine allowed for variation in the completeness of the specimens collected but had little effect on the $N$ estimates.

There was a slight fall in the baseline $F_{1} V_{1}$ during the course of the study irrespective of diet and a further $\omega$ slight fall when subjects were taking the sodium $<$ tablets. These changes were, however, small and not ${ }^{\circ}$ significant. Allowing for the change in $\mathrm{FEV}_{1}$ made little difference to the relation between bronchial ${ }^{+}$ reactivity and sodium excretion (table 4).

All subjects were asked not to use beta agonist $\frac{\overrightarrow{1}}{\mathrm{~T}}$ inhalers within six hours of a challenge test. Two men $\frac{?}{\vec{P}}$ and three women used their inhalers within this period $\stackrel{\mathbb{}}{\circ}$ at some time during the trial. Adjusting for changes in 


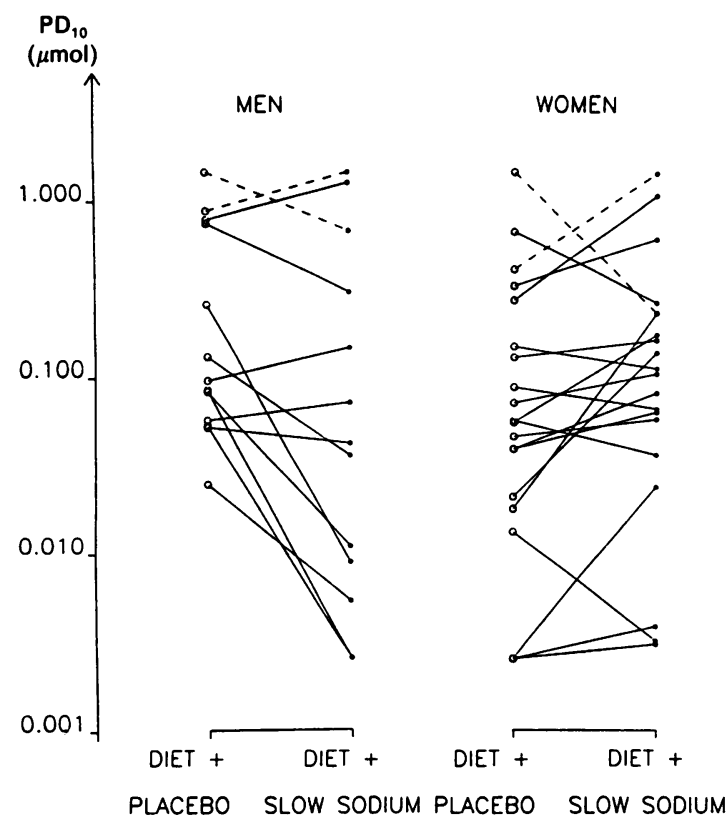

Fig 2 Changes in PD values (airway reactivity) for men and women taking slow sodium and placebo tablets. Broken lines represent subjects for whom one estimate of $P D_{10}$ was censored.

the period in which people had used inhalers made no difference to the results.

The magnitude of the relation between bronchial reactivity and sodium excretion was not dependent on age or mean skin weal diameter. The age range in this study was narrow, however, and all but four of the subjects were atopic.

There was no significant association between systolic or diastolic blood pressure and sodium excretion

Table 2 Differences in dose of histamine required to provoke a $20 \%\left(P D_{20}\right)$ or $10 \%\left(P D_{10}\right)$ fall in $F E V_{1}$ during the slow sodium and the placebo period

\begin{tabular}{lll}
\hline & \multicolumn{2}{l}{$\begin{array}{l}\text { Change in provoking dose (95\% confidence } \\
\text { interval) expressed as doubling concentration of } \\
\text { histamine }\end{array}$} \\
\cline { 2 - 3 } & Mean change & (95\% confidence interval) \\
\hline $\begin{array}{l}\text { Men } \\
\mathrm{PD}_{20}(\mathrm{n}=11)^{*}\end{array}$ & -1.51 & $(-2.72$ to -0.31$)$ \\
$\mathrm{PD}_{10}(\mathrm{n}=13)$ & -1.66 & $(-2.95$ to -0.38$)$ \\
$\begin{array}{l}\text { Women } \\
\mathrm{PD}_{20}(\mathrm{n}=20)\end{array}$ & 0.12 & $(-0.99$ to 1.23$)$ \\
$\mathrm{PD}_{10}(\mathrm{n}=20)$ & 0.62 & $(-0.15$ to 1.39$)$
\end{tabular}

* One man had two censored $\mathrm{PD}_{10}$ values and three had two censored $P_{2}$ values and so could not be included in these analyses. $\mathrm{PD}_{20}, \mathrm{PD}_{10}$ - provocative doses of histamine causing $\mathrm{FEV}$, to fall by $20 \%$ and $10 \%$.
Table 3 Association within subjects between $P D_{20}$ as the dependent variable and urinary excretion of sodium $\left(\mathrm{Na}^{+}\right)$, potassium $\left(\mathrm{K}^{+}\right)$, and creatinine

\begin{tabular}{|c|c|c|c|c|}
\hline & \multirow[b]{2}{*}{ Method } & \multicolumn{3}{|c|}{ Regression coefficient ( $S E$ ) } \\
\hline & & $\mathrm{Na}^{+}$ & $K^{+}$ & Creatinine \\
\hline$\stackrel{M e n}{(n=14)}$ & $\begin{array}{l}\text { GLIM } † \\
\text { WOLYNETZ† }\end{array}$ & $\begin{array}{c}-0.0050^{*} \\
(0.0019) \\
-0.0055^{* *} \\
(0.0017)\end{array}$ & $\begin{array}{c}0.0017 \\
(0.0089) \\
0.0058 \\
(0.0083)\end{array}$ & $\begin{array}{c}0.0163 \\
(0.0431) \\
0.0137 \\
(0.0384)\end{array}$ \\
\hline $\begin{array}{l}\text { Women } \\
(\mathrm{n}=22)\end{array}$ & $\begin{array}{l}\text { GLIM } \\
\text { WOLYNETZ }\end{array}$ & $\begin{array}{c}0.0013 \\
(0.0021) \\
0.0019 \\
(0.0018)\end{array}$ & $\begin{array}{c}0.0077 \\
(0.0063) \\
0.0062 \\
(0.0054)\end{array}$ & $\begin{array}{c}0.0054 \\
(0.0480) \\
0.0130 \\
(0.0406)\end{array}$ \\
\hline
\end{tabular}

†Used with censored values set to the censoring limit and assumed exact.

fIncorporates the knowledge that censored values were known only to be $\geqslant 1.45 \mu \mathrm{mol}$ (see text).

${ }^{*} p<0.05 ;{ }^{* *} p<0.01$.

for either sex (table 5). In men there was a negative association between diastolic blood pressure and urinary excretion of potassium $(p<0.05)$. The associations between blood pressure and urinary excretion of potassium in women were weak, positive, and not significant.

\section{Discussion}

In a randomised, double blind, crossover challenge the bronchial response to histamine was greater in men on a low sodium diet while they were taking slow sodium than when they were taking placebo. Similar changes were not seen in women. Change in airway reactivity in the men was associated with change in urinary sodium excretion.

The sodium excretion of the subjects was low at the beginning of the trial. The mean excretion was $106 \mathrm{mmol} / 24$ hours compared with $170 \mathrm{mmol} / 24$ hours in a sample of 138 men living in North

Table 4 Effect of adjusting for other variables on the regression coefficients $\left(P D_{10}\right)$ for sodium $\left(\mathrm{Na}^{+}\right)$excretion (estimates used maximum likelihood to take account of censoring $)^{*}$

\begin{tabular}{|c|c|c|}
\hline & \multicolumn{2}{|c|}{$\begin{array}{l}\text { Regression coefficient for sodium } \\
\text { excretion }(S E)\end{array}$} \\
\hline & Men & Women \\
\hline $\begin{array}{l}\mathrm{Na}^{+}+\mathrm{K}^{+}+\mathrm{cr} \\
\quad+\text { initial FEV } \\
\quad+\text { last dose of }\end{array}$ & $\begin{array}{l}-0.0055^{* *}(0.0017) \\
-0.0054^{* *}(0.0016) \\
-0.0054^{* *}(0.0017)\end{array}$ & $\begin{array}{l}0.0019(0.0018) \\
0.0027(0.0019) \\
0.0012(0.0017)\end{array}$ \\
\hline+ diet & $-0.0057^{* *}(0.0018)$ & $0.0024(0.0018)$ \\
\hline
\end{tabular}

*All models are within subject analyses and are adjusted for the effects of potassium $\left(\mathrm{K}^{+}\right)$and creatinine $(\mathrm{cr})$ excretions in table 3 . ${ }^{* *} \mathrm{p}<0.01$. 
Table 5 Within subject regression of blood pressure against 24 hour urinary electrolytes

\begin{tabular}{|c|c|c|c|}
\hline & \multicolumn{2}{|c|}{ Regression coefficients ( $S E$ ) } & \multirow[b]{2}{*}{ Creatinine } \\
\hline & $\mathrm{Na}^{+}$ & $\boldsymbol{K}^{+}$ & \\
\hline $\begin{array}{c}\text { Men }(n=14) \\
\text { Systolic } \\
\text { Diastolic }\end{array}$ & $\begin{array}{l}0.065(0.042) \\
0.019(0.025)\end{array}$ & $\begin{array}{l}-0.298(0 \cdot 198) \\
-0.255^{*}(0 \cdot 118)\end{array}$ & $\begin{array}{l}1.48(0.96) \\
0.91(0.57)\end{array}$ \\
\hline $\begin{array}{l}\text { Women }(\mathrm{n}= \\
\text { Systolic } \\
\text { Diastolic }\end{array}$ & $\begin{array}{l}0.036(0.041) \\
0.008(0.027)\end{array}$ & $\begin{array}{l}0.091(0.124) \\
0.069(0.081)\end{array}$ & $\begin{array}{l}-0.45(0.95) \\
-0.54(0.62)\end{array}$ \\
\hline
\end{tabular}

Hampshire and in a similar trial looking at the effect of altering sodium intake on blood pressure. " This may have been due to the selection of subjects. Alternatively, as all the subjects were told the hypothesis when they gave their consent to the study, some may have reduced their sodium intake during the initial week of the study even though they were asked not to. This low initial level of sodium excretion may explain the relatively small mean fall in sodium excretion of about $35 \mathrm{mmol} / 24$ hours with the change to a low sodium diet. The mean increase in sodium excretion during the slow sodium period compared with the placebo period was also smaller than might have been expected. The total daily dose of sodium was $80 \mathrm{mmol}$, but the mean increase in sodium excretion was only $47 \mathrm{mmol} / 24$ hours in men and $43 \mathrm{mmol} / 24$ hours in women. Compliance as judged by pill counts at the end of each period was good and lapses in compliance could not explain such a small change. Possibly the increase in sodium intake caused by the slow sodium tablets reduced the appetite for salt and made it easier to comply with the low salt diet.

All the subjects included in the analysis were moderately reactive to inhaled histamine. Less reactive subjects were excluded on clinical criteria and by the requirement that at least one of the last three estimates of $\mathrm{PD}_{10}$ should be uncensored-that is, less than $1.45 \mu \mathrm{mol}$ of histamine. The censoring value was lower than usual because of an error in making up the histamine solutions. The censoring value was set at twice the maximum cumulative dose of histamine administered as this degree of extrapolation has been shown to give estimates that are no less reliable than those confined to doses less than the maximum cumulative dose. $^{8}$

Where values of $\mathrm{PD}_{10}$ were greater than $1.45 \mu \mathrm{mol}$ a more exact estimate was not possible and this caused difficulties in analysing the data. Fixing these values at the censoring limit of $1.45 \mu \mathrm{mol}$ underestimates the differences from any values below the censoring limit. Excluding subjects with any censored values, however, loses valuable information on the minimum difference between the two values. Provided that the within person distribution of $\log \mathrm{PD}_{10}$ can reasonably be $\overrightarrow{\bar{F}}$ assumed to be normal, maximum likelihood methods can be used to estimate regression coefficients where $\frac{C}{\sigma}$ the dependent variable has censored values. ${ }^{10}$ As $\overline{\bar{c}}$ would be expected, the regression coefficients were $\widehat{\widetilde{\Phi}}$ slightly greater when estimated in this way and the standard errors slightly less.

When censored values have to be set to the censor- $\vec{\circ}$ ing limit $P D_{10}$ may be preferred to $P D_{20}$ if this leads to fewer censored values in the analysis. Differences $\vec{\sigma}$ between a censored value that has been set to the $\Rightarrow$ censoring limit and another value will always under- $-x$ estimate the true difference and will therefore provide $\overrightarrow{+}$ biased estimates of the overall effect. In this study there was little difference in the estimated effecto whether $\mathrm{PD}_{10}$ or $\mathrm{PD}_{20}$ was used for men, among whom? two subjects had censored information on oneoccasion each in the trial whichever measurement was used. On the other hand, the differences among the women were greater; this is in part due to the censoringe of values from only one woman when $\mathrm{PD}_{10}$ was used but from four women when $\mathrm{PD}_{20}$ was used.

In the regression of reactivity against urinary elec-. $-\oplus$ trolytes, one subject had all the last three values of $\mathrm{PD}_{20}$ censored and had to be excluded from that analysis. When maximum likelihood estimates of the regression coefficients were used to minimise the effecto of censoring, reactivity measured by $\mathrm{PD}_{20}$ was also $\$$ significantly associated with sodium excretion $(\beta=\overrightarrow{\vec{B}}$ $-0.0041, \mathrm{SE}=0.0017 ; \mathrm{n}=13: \mathrm{p}<0.05)$ in men.

An association was found between bronchial reactivity and sodium excretion for men but not for women. The difference between the two sexes is significant and is in keeping with the relation betweeno salt purchases and asthma mortality. ${ }^{2}$ This differs from $\underset{\times}{\mathscr{D}}$ the results of Javaid et al, who also found an increaseoin bronchial response to histamine when subjects 3 . increased dietary sodium, but no difference between the response of six men and four women. ${ }^{12}$ This study, however, was small, open, and unrandomised, makingo it difficult to interpret with confidence.

Nevertheless, as the basic pathogenetic mechanisms are likely to be the same for both sexes, this difference requires some explanation. The most likely explana-o tion is some confounding factor obscuring the underlying relation between the two variables in the women. As our measurements were taken two weekso apart possibly our results are confounded by an effecto of the menstrual cycle. But although asthmatic symp $\frac{\pi}{0}$ toms have been shown to vary with the menstrualos cycle $^{13-16}$ reactivity has generally not varied ${ }^{16-17}$ though there are clearly some exceptions. ${ }^{18}$ We analysed datao

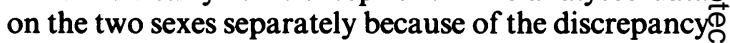
between the sexes in the regional mortality datad showing an association between asthma mortality and table salt consumption for men and for children of 
both sexes but no such association for adult females. ${ }^{2}$ An additional cyclical source of within subject variability, presumably common to most women of childbearing age, would not be expected to obscure an effect of sodium consumption on annual asthma mortality. A second possibility therefore is that airway responsiveness in women is not affected by an increased sodium intake.

There is some support for this from the difference in the relation between blood pressure and electrolyte excretion that has been reported for men and women. Belgian $^{19}$ and British ${ }^{20}$ studies have noted that blood pressure is related to urinary potassium excretion in men, but not in women unless they are taking a contraceptive pill. ${ }^{20}$ Our findings give some support to these observations, though the numbers are small. Diastolic blood pressure was related negatively to potassium excretion in men $(p<0.05)$, whereas the relation was weak and positive for the women. The discrepancy between the sexes in the effects of dietary electrolytes may therefore be a general one, not confined to an effect on either airway reactivity or blood pressure. Here again, however, the data are not all consistent. Neither the Intersalt study ${ }^{21}$ nor the Scottish heart health study ${ }^{22}$ show the same discrepancy between the effects of sodium or potassium on blood pressure.

This study supports the hypothesis that a high sodium diet increases bronchial reactivity in men but not in women and suggests that moderate restriction of sodium intake in asthmatic men would reduce bronchial reactivity. The analysis of mortality data ${ }^{2}$ suggests that this may also be true for children and that an overall reduction in sodium intake might reduce mortality from asthma in these groups.

We are grateful to Professor David Morrell and the partners of the Lambeth Road group practice, Dr Andrew Harris, and the chest physicians of St Thomas's Hospital for allowing us to contact their patients. Mary Evans contacted many of these patients on our behalf. Dr C W Jones of Ciba-Geigy Pharmaceuticals generously provided us with the slow sodium and placebo tablets. Olia Papacosta helped with the initial randomisation and assembly of the data, and Dr Fiona North helped with the data collection. SC and TDJ are supported by the Department of Health and JEN was supported by the Asthma Research Council. We would like to thank Professor W W Holland for his continued encouragement and support.

\section{References}

1 Burney PGJ, Britton JR, Chinn S, et al. Response to inhaled histamine and 24 hour sodium excretion. $\mathrm{Br}$ Med J 1986;292:1483-6.

2 Burney PGJ. A diet rich in sodium may potentiate asthma: epidemiological evidence for a new hypothesis. Chest 1987;91(suppl):143-8S.

3 Godfrey RC. Asthma and IgE levels in rural and urban communities in The Gambia. Clin Allergy 1975;5: 201-7.

4 Anderson HR. Respiratory abnormalities in Papua New Guinea children: the effects of locality and domestic wood smoke. Int J Epidemiol 1978;7:63-72.

5 Van Niekerk CH, Weinberg EG, Shore SC, Heese H de V, van Schalkwyk DJ. Prevalence of asthma in Xhosa children: a comparative study of urban and rural Xhosa children. Clin Allergy 1979;9:319-24.

6 Waite DA, Eyles EF, Tonkin SL, O'Donnell TV. Asthma prevalence in Tokeluan children in two environments. Clin Allergy 1980;10:71-5.

7 Yan K, Salome C, Woolcock AJ. Rapid method for measurement of bronchial responsiveness. Thorax 1983;38:760-5.

8 Chinn S, Britton JR, Burney PGJ, Tattersfield AE, Papacosta AO. Estimation and repeatability of the response to inhaled histamine in a community survey. Thorax 1987;42:45-52.

9 Baker RJ, Nelder JA. The GLIM system. Release 3. Oxford: Numerical Algorithms Group, 1978.

10 Wolynetz MS. AS139 Maximum likelihood estimation in a linear model from confined and censored normal data. Applied Statistics 1979;28:195-206.

11 MacGregor GA, Markandu ND, Best FE, et al. Doubleblind randomised cross-over trial of moderate sodium restriction in essential hypertension. Lancet 1982;i:351-5.

12 Javaid A, Cushley MJ, Bone MF. Effect of dietary salt on bronchial reactivity to histamine in asthma. $\mathrm{Br} \mathrm{Med} \mathrm{J}$ 1988;297:454.

13 Hanley SP. Asthma variation with menstruation. $\mathrm{Br} J \mathrm{Dis}$ Chest 1981;75:306-8.

14 Gibbs CJ, Coutts H, Lock R, Finnegan OC, White RJ. Premenstrual exacerbation of asthma. Thorax 1984;39:833-6.

15 Eliasson O, Scherzer HH, De Graff AC. Morbidity in asthma in relation to the menstrual cycle. J Allergy Clin Immunol 1986;77:87-94.

16 Juniper EF, Kline PA, Roberts RS, Hargreave FE, Daniel EE. Airway responsiveness to metacholine during the natural menstrual cycle and the effect of oral contraceptives. Am Rev Respir Dis 1987;135:1039-42.

17 Black PN. Changes in airway beta-adrenergic responses during the menstrual cycle with premenstrual asthma [abstract]. Thorax 1987; 43:232.

18 Beynon HLC, Garbett ND, Barnes PJ. Severe premenstrual exacerbations of asthma: effect of intramuscular progesterone Lancet 1988;ii:370-2.

19 Staessen J, Bulpitt CJ, Fagard R, Joossens JV, Lijnen P, Amery A. Contraceptive pill use, urinary sodium and blood pressure: a population study in two Belgian towns. Acta Cardiol 1984;39:55-64.

20 Bulpitt CJ, Broughton PMG, Markowe HLJ, et al. The relationship between both sodium and potassium intake and blood pressure in London Civil Servants. $J$ Chron Dis 1986;39:211-9.

21 Intersalt Cooperative Research Group. Intersalt: an international study of electrolyte excretion and blood pressure. Results for 24 hour urinary sodium and potassium excretion. Br Med J 1988;297:319-28.

22 Smith WCS, Crombie IK, Tavendale RT, Gulland SK, Tunstall-Pedoe HD. Urinary electrolyte excretion, alcohol consumption, and blood pressure in the Scottish heart health study. Br Med J 1988;297:329-30. 